\title{
Functional outcomes following ileal pouch-anal anastomosis (IPAA) in older patients: a systematic review
}

\author{
Lisa Ramage $^{1,2} \cdot$ Sheng Qiu ${ }^{1,2} \cdot$ Panagiotis Georgiou ${ }^{1,2} \cdot$ Paris Tekkis ${ }^{1,2} \cdot$ Emile Tan $^{1,2}$
}

Accepted: 14 December 2015 / Published online: 12 January 2016

(C) The Author(s) 2016. This article is published with open access at Springerlink.com

\begin{abstract}
Aim Ileal pouch-anal anastomosis (IPAA) is performed in ulcerative colitis or familial adenomatous polyposis with a view to restoration of GI continuity and prevention of permanent faecal diversion. Debate exists as to its safety in older patients. This review aims to assess functional outcomes and safety of restorative proctocolectomy (RPC) in older compared to younger patients.

Methods Literature search was performed for age-stratified studies which assessed functional outcomes of IPAA. Twelve papers were included overall. Patients were categorized into 'older' and 'younger' groups. Analysis was split into three separate parts: 1 . Age cut-off of $50 \pm 5$ years (with sensitivity analysis); 2 . Age cut-off of $65 \pm$ years; 3 . Longterm outcomes ( $>10$ years).

Results With an age cut-off of 50 years (4327 versus 513 patients), complication rates were comparable with the exception of an increased rate of small-bowel obstruction in the younger patients $(p=0.034)$. At 1 year, 24-h stool frequency was significantly higher in the older patient group $(p<0.0001)$. Daytime $(p<0.0001)$ and night-time $(p<0.0001)$ incontinence rates were also significantly higher in older patients.

Overall, function deteriorated with time across all ages; however, after 10 years, there was no significant difference in incontinence rates between age groups.
\end{abstract}

Emile Tan

e.tan@imperial.ac.uk

1 Colorectal Surgery, Imperial College London, London, UK

2 Department of Surgery and Cancer, Chelsea and Westminster Hospital, 369 Fulham Road, London SW10 9NH, UK
Dehydration and electrolyte loss was a significant problem in patients over $65(p<0.0001)$.

Despite differences in postoperative function, quality of life was comparable between groups; however, only a few studies reported quality of life data.

Conclusion IPAA is safe in older patients, although treating clinicians should bear in mind the increased risk of dehydration. Postoperative function is worse in older patients, but seems to level out with time and does not appear to significantly impact on overall quality of life and patient satisfaction. Assessment for suitability for RPC should not be based on chronological age in isolation. It is imperative that the correct support is given to older patients with worsened postoperative function in order to maintain patient satisfaction and adequate quality of life.

Keywords Ileal pouch-anal anastomosis (IPAA) $\cdot$ Restorative proctocolectomy $(\mathrm{RPC}) \cdot$ Age $\cdot$ Postoperative function

\section{Introduction}

Restorative proctocolectomy (RPC), also known as ileal pouch-anal anastomosis (IPAA) is typically performed in patients with familial adenomatous polyposis (FAP) or ulcerative colitis (UC). It can be performed either as a single-stage procedure or, in cases where emergency surgery has been required, as a completion proctectomy with pouch formation following emergency colectomy.

In the elderly, the majority of cases are performed in the context of UC which is non-responsive to maximal medical therapy or where there is evidence of associated dysplasia or malignancy [1]. Originally, the general consensus was that surgery in those over 50 should undergo proctocolectomy with formation of an end ileostomy, as the associated morbidity with 
IPAA was too high for older patients. However, several papers have documented similar outcomes with IPAA in terms of safety when compared to younger patients [2-4].

This review paper aims to examine the functional outcomes following IPAA in older versus younger patients. This will be performed through analysis of published literature undertaking age-related analysis of functional outcomes with IPAA.

\section{Methods}

The systematic review was undertaken in accordance with the PRISMA (Preferred Reporting Items for Systematic Reviews and Meta-Analyses) guidelines. Two reviewers (LR and SQ) performed the literature search and data extraction independently. PubMed, Medline and Google scholar databases were searched for relevant articles. The following keywords and phrases were used in various combinations: age, function, outcome, elderly, ileoanal pouch, ileal anal-pouch anastomosis (IPAA) ileal pouch, restorative, proctocolectomy.

All articles identified within the initial search were screened for relevance and content, and their bibliographies searched for any additional relevant articles. Abstracts were initially screened by title and abstract content for relevance. In cases where relevance was uncertain, the papers were scanned for the relevant data.

The criteria for inclusion were as follows: 1 . Articles considering postoperative functional outcomes with IPAA stratified according to patient age. 2. Ileoanal pouch formation for any disease condition (e.g. ulcerative colitis, familial adenomatous polyposis).

Exclusion criteria were as follows: 1 . No discussion of at least one functional outcome of interest (see below), 2. Noncomparative papers, case reports and review papers. 3. Papers where age has been found to be a significant factor in outcome through multivariate analysis; however, no further information has been provided. 4. Papers published in an alternative language to English where translation was not available. 5. Papers where the 'older' age group cut-off was younger than 45 years.

All publications up to and including 1 February 2015 were considered. Major outcomes of interest were as follows:

1. Postoperative complications

2. Bowel frequency

3. Incontinence

4. Use of pads/medications

5. Quality of life (QoL) data

6. Patient satisfaction

7. Sexual function

8. Long-term data ( $>10$ years)

Data extraction was undertaken independently by two of the authors (LR and SQ) using the pre-determined outcome measures. There were no discrepancies between them.
The following data points were extracted (where presented) from each paper:

Trial design, patient subgroups, sex ratio, diagnosis, indication for surgery, surgery performed, comorbidities, pouch configuration, use of covering ileostomy, handsewn or stapled anastomosis, length of follow-up, postoperative complications.

Functional outcomes: number of bowel movements per $24 \mathrm{~h}$, number of movements/day, number of movements/ night, pad usage, seepage, incontinence, urgency, deferral time, use of anti-diarrhoeals.

Anorectal physiology results: maximum/mean resting pressures, maximum/mean squeeze pressures, threshold and maximum tolerated volumes.

In addition to this, quality of life data, sexual function and patient satisfaction data were also retrieved where given.

\section{Statistical analysis}

Due to the heterogeneity of presented data, it was often not feasible to perform statistical analysis. Means were combined to give weighted means for overall results. In cases where a median has been given, this was converted to a mean using the method described by Hozo and colleagues [5]. Student's $t$ test was used to compare continuous data, and chi-squared $2 \times 2$ contingency table was used to compare categorical data.

\section{Results}

Figure 1 demonstrates the literature search results. Following exclusion of duplicates, 1103 abstracts were returned through the use of the search terms. A total of 729 papers were excluded based on title alone; 374 abstracts were reviewed for content and 348 were excluded.

A total of 26 papers were identified which contained data regarding age and functional outcomes with restorative proctocolectomy. Twenty-one papers were identified with documented comparative functional outcomes with IPAA across different age groups. One was excluded as this was a case report, and another was excluded as the article was available in Spanish only. The paper written by Pemberton et al. [6] was also excluded as this did not contain the numbers of patients in each sub-group; therefore, incorporation of data into the analysis was not possible.

Of the 18 papers left, five were found to be from the Cleveland Clinic Florida. Four papers contained overlapping patient data [7-10]. The paper by Ho et al. [10] was included as this was the most recent data; however, outcomes from Takao et al. [9] were included in discussion which were not featured in the more recent paper (anorectal physiology, patient satisfaction, incontinence scoring system). 
Fig. 1 Flow chart of literature review

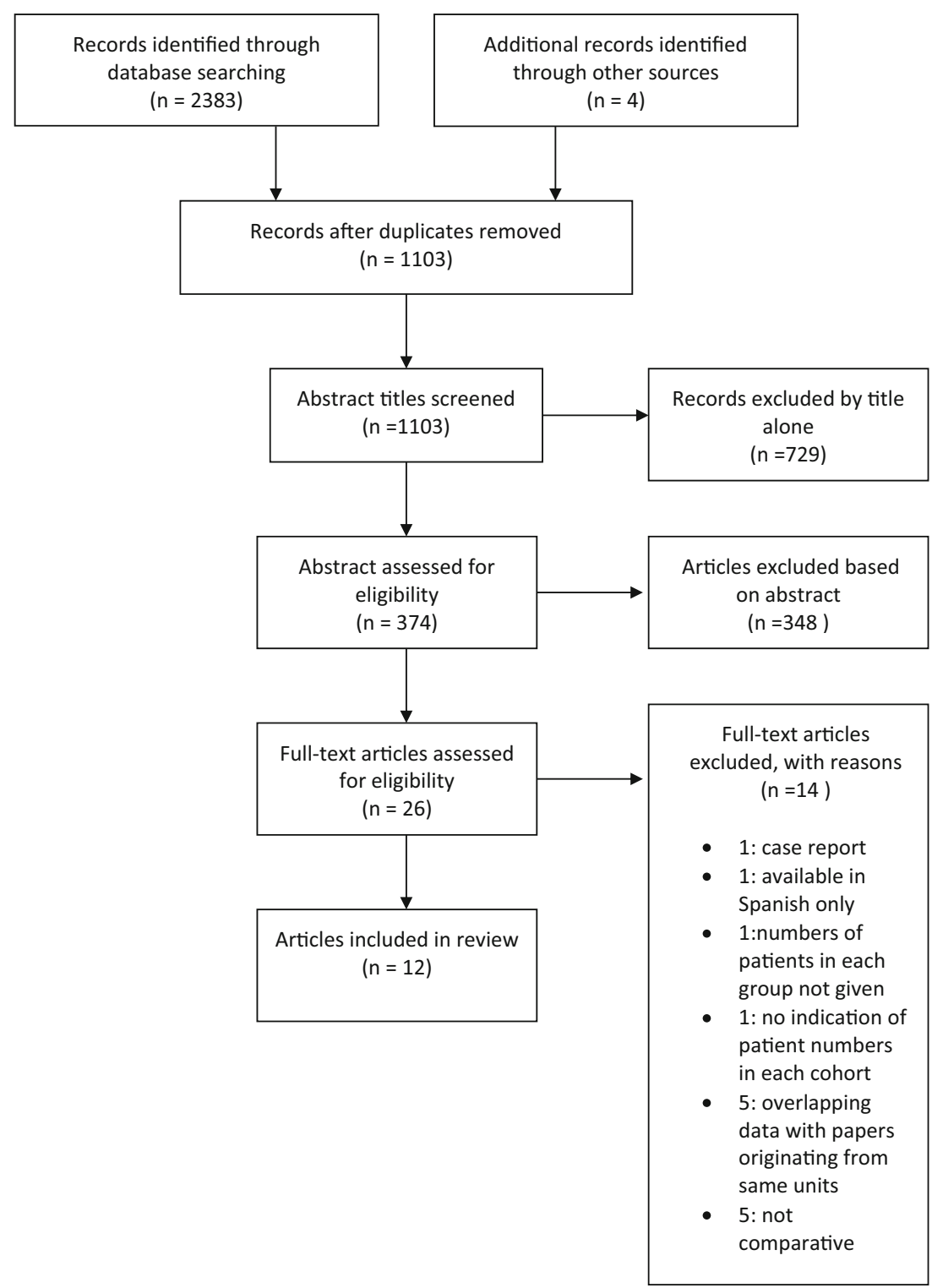

Likewise, further three papers [10-13] originated from the same unit (Mayo clinic, Minnesota). The most recent data from Chapman et al. [13] was included in analysis.

Finally, there were three papers from the Cleveland Clinic in Ohio with overlapping patient data [14-16]. The 2003 paper written by Delaney and colleagues contained more short-term data, whereas the paper by Kiran et al. was concerned more with long-term functional results, with a follow-up of 15 years. Therefore, results published at the 1 year mark from Delaney et al. were used in the general analysis, with long-term results (at 15 years follow-up) taken from the paper by Kiran et al.

Overall, there were 12 papers included in this review. Study characteristics are given in Table 1.

Patient age stratification was non-uniform across the papers. In addition, some studies considered longer-term follow-up. Therefore, in order to allow for data comparison, papers were considered as follows:
1. Patients were divided into a 'younger' and 'older' group with a cut-off age range of $50 \pm 5$ years. In studies where an age group spanned the cut-off range, i.e. $46-55$, these patients were excluded from analysis $[9,13,16]$. Where data had been grouped into three or more comparative groups, the results were pooled into the two age categories in order to allow comparison of data. Results were weighted according to patient numbers in each age category. Nine papers satisfied the above criteria and were analysed together $[1,9,10,13,16-20]$.

2. Separate sensitivity analysis was performed with a strict age cut-off of 50 years. Six papers were included [1, 10, $13,16,18,20]$. All compared outcomes for sections 1 and 2 were extracted at the 1-year (or earliest short-term) point.

3. Long-term outcomes ( $>10$ years) were considered by three authors $[13,15,16]$. Data was extracted 


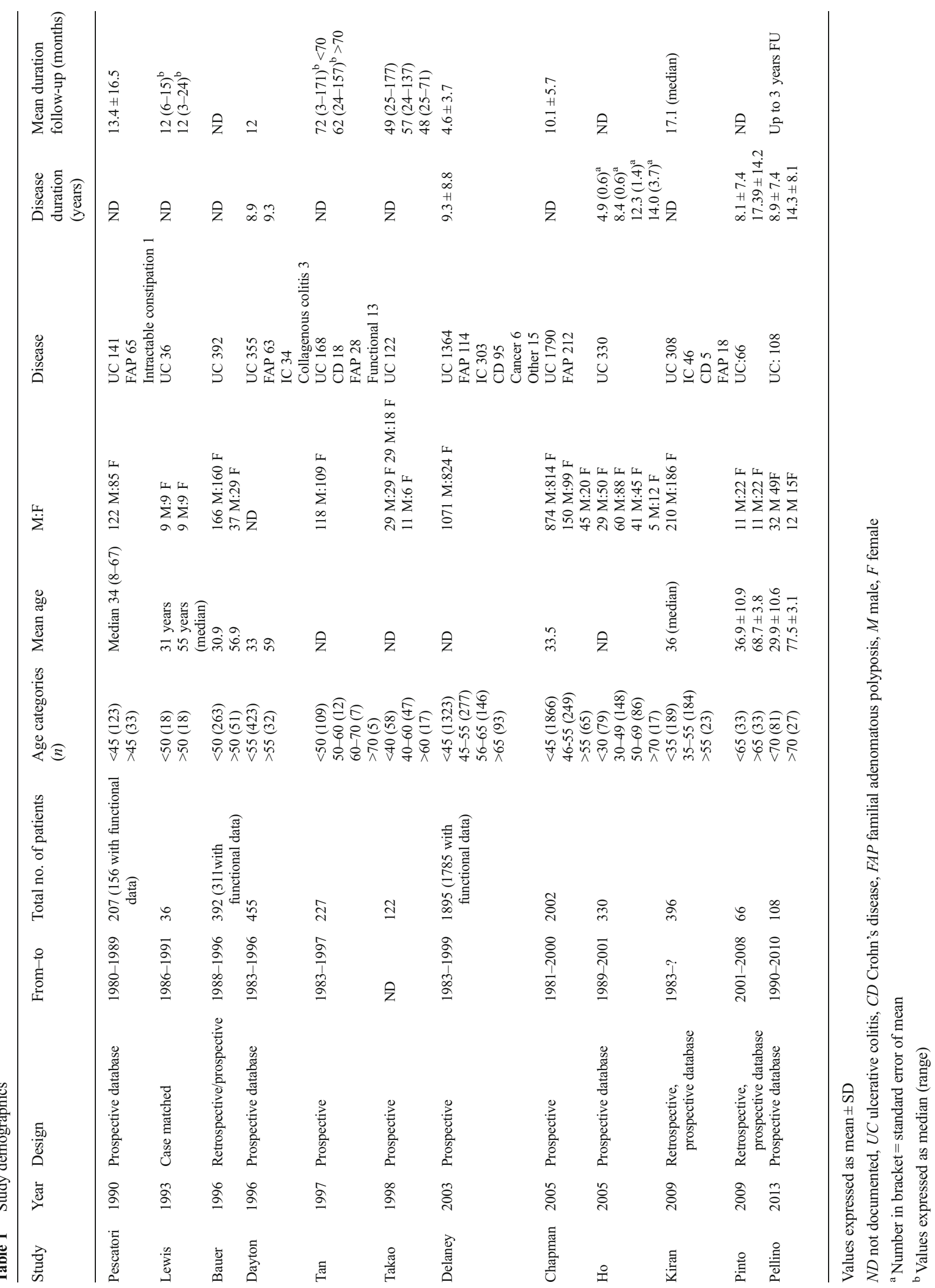


preferentially from the paper by Kiran et al. as followup stretched to 15 years. Additionally, in the paper by Delaney et al., it was difficult to determine the number of patients who were followed up for the entire 10 -year period.

4. Two papers $[2,21]$ categorised 'older' patients as above the $50 \pm 5$ year cut-off. Therefore, they were considered separately alongside data from Ho et al. [10] and Delaney et al. [16] who had separate outcome data for patients $>65$ \pm 5 years.

Table 2 displays the reported outcomes of interest for each paper.

\section{A comparative analysis of patients with age cut-off of $\mathbf{5 0}$ \pm 5 years}

There were 4327 versus 513 patients across the nine included papers. Table 3 describes the operative details for each study. Table 4 gives the age grouping breakdown from each paper.

\section{Surgical complications}

Six papers $[1,10,13,16,19,20]$ discussed postoperative complications (Table 5). With the exception of small-bowel obstruction, which was significantly more common in younger patients $(p=0.034)$, there were no other differences identified in overall complication rates. There did however appear to be a trend towards increased rates of pouchitis in younger patients, although this did not reach statistical significance $(p=0.058)$. There was also a trend demonstrating towards a higher mortality rate in older patients $(p=0.070)$. Delaney et al. [16] showed a significantly higher pouch failure rate in those over 55 years of age at time of surgery $(p<0.000001)$; however, this result is not reflected in the overall analysis. Dayton et al. [19] documented that older patients were significantly more likely to be readmitted to hospital with dehydration $(p=<0.01)$.

Functional outcomes Functional outcomes were considered in all included papers. Due to the heterogeneity of reporting methods used, overall statistical comparisons have been made where data presentation has allowed.

Mean number of bowel motions/24 h Four studies reported the mean bowel movements per $24 \mathrm{~h}[1,10,18,19]$. Mean weighted bowel frequency per $24 \mathrm{~h}$ was $5.55 \pm 1.48$ versus $6.79 \pm 3.39$ motions in the younger $(n=994)$ and older $(n=219)$ groups (unpaired $t$ test, $p<0.0001)$.

Daytime and nocturnal bowel motions Three papers considered bowel frequency as day and night motions $[1,13,16]$. Additionally, Dayton et al. [19] gave a separate nocturnal

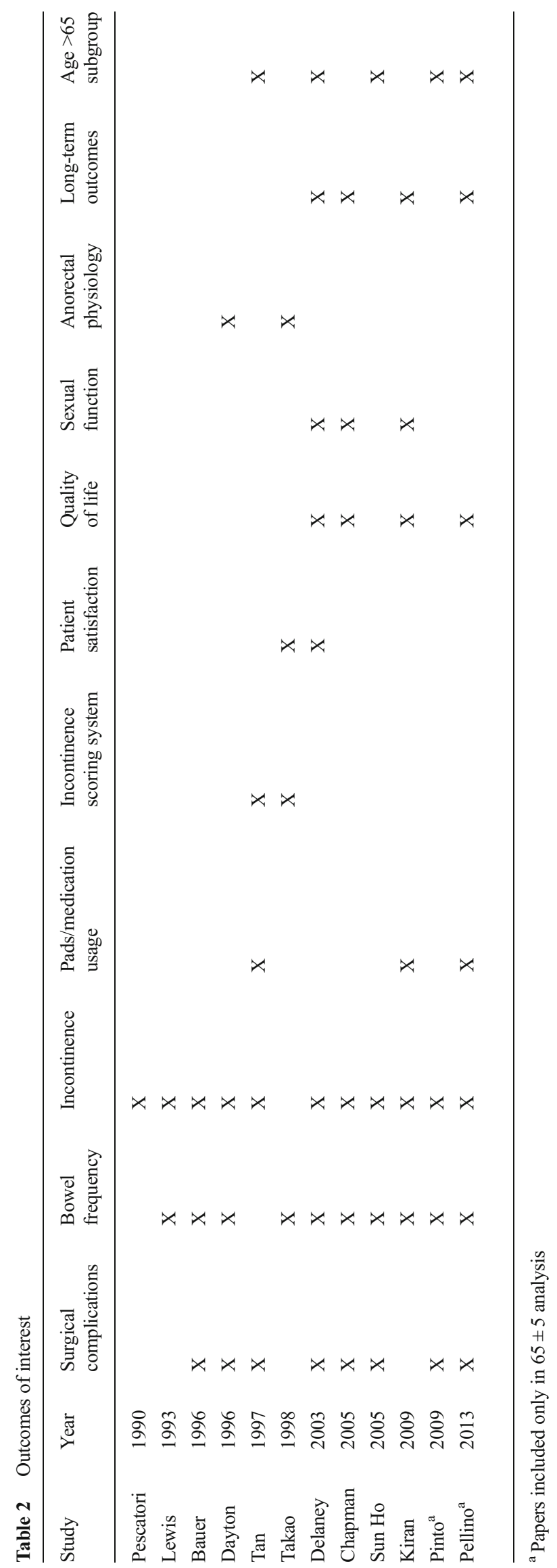




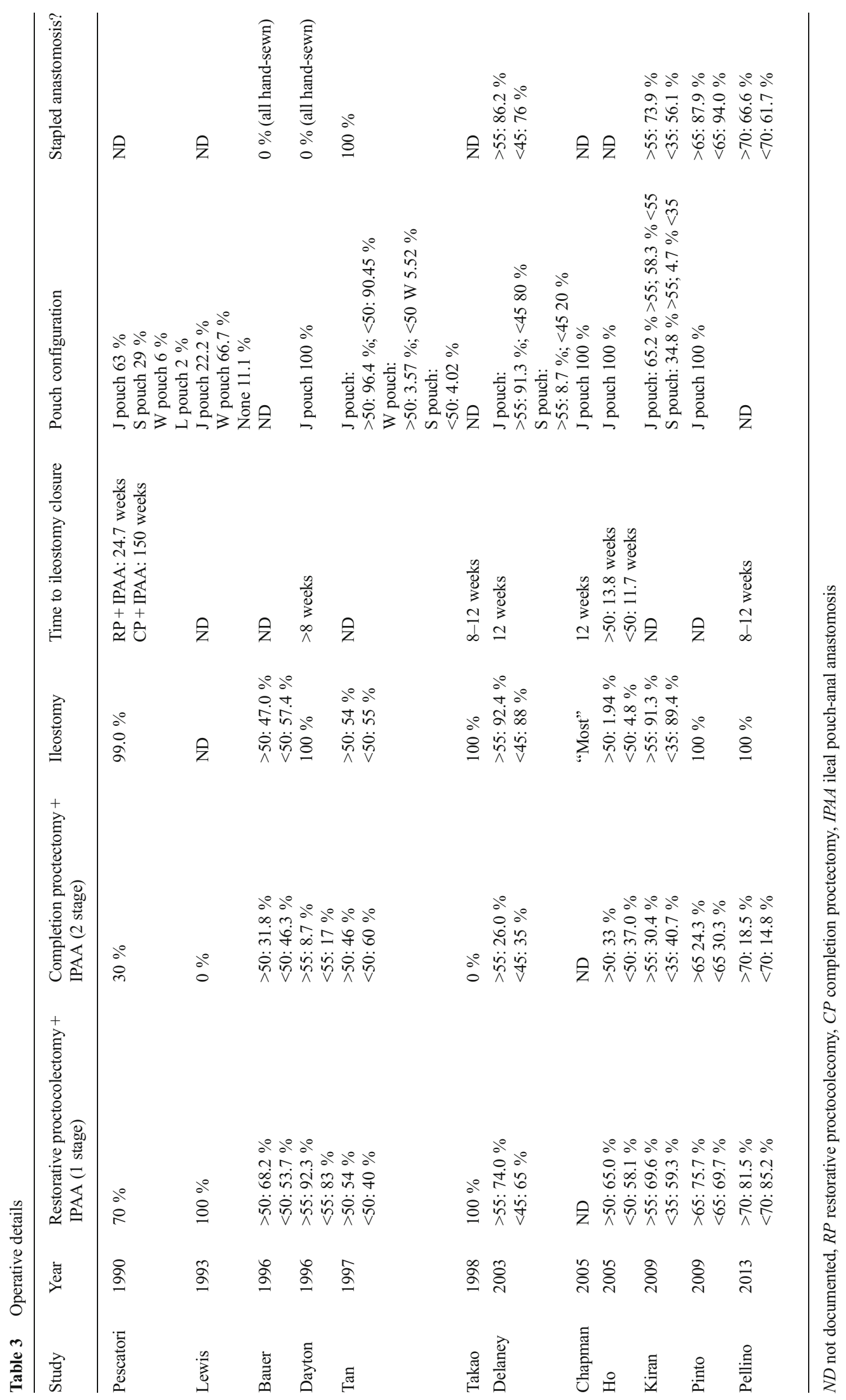


Table 4 Older and younger age groupings

\begin{tabular}{|c|c|c|c|}
\hline Study & $\begin{array}{l}\text { Age groups } \\
\text { in study }\end{array}$ & $\begin{array}{l}\text { Younger } \\
\text { group }(N)\end{array}$ & $\begin{array}{l}\text { Older } \\
\text { group }(N)\end{array}$ \\
\hline Takao $^{a}$ & $\begin{array}{l}<40 \\
41-60^{b} \\
>60\end{array}$ & $<40(58)$ & $>60(17)$ \\
\hline Pescatori & $\begin{array}{l}<45 \\
>45\end{array}$ & $<45(123)$ & $>45(33)$ \\
\hline Dayton & $\begin{array}{l}<55 \\
>55\end{array}$ & $<55(423)$ & $>55(32)$ \\
\hline Chapman $^{\mathrm{c}}$ & $\begin{array}{l}<45 \\
46-55^{\mathrm{b}} \\
>55\end{array}$ & $<45(1688)$ & $>55(65)$ \\
\hline Delaney $^{\mathrm{c}, \mathrm{d}, \mathrm{e}}$ & $\begin{array}{l}<45 \\
46-55^{\mathrm{b}} \\
56-65 \\
>65\end{array}$ & $<45(1323)$ & $>55(168)$ \\
\hline Sun $\mathrm{Ho}^{\mathrm{c}, \mathrm{d}}$ & $\begin{array}{l}<30 \\
30-49 \\
50-69 \\
>70\end{array}$ & $<50(227)$ & $>50(103)$ \\
\hline Lewis ${ }^{\mathrm{c}}$ & $\begin{array}{l}<50 \\
>50\end{array}$ & $<50(18)$ & $>50(18)$ \\
\hline Bauer $^{\mathrm{c}}$ & $\begin{array}{l}<50 \\
>50\end{array}$ & $<50(326)$ & $>50(66)$ \\
\hline $\operatorname{Tan}^{\mathrm{c}, \mathrm{d}}$ & $\begin{array}{l}<50 \\
>50\end{array}$ & $<50$ (199) & $>50(28)$ \\
\hline Total & & 4327 & 513 \\
\hline
\end{tabular}

${ }^{\text {a }}$ Outcomes compared: anorectal physiology, patient satisfaction, incontinence scoring system, otherwise excluded in analysis

${ }^{\mathrm{b}}$ Patient group excluded as spanning cut-off

${ }^{\mathrm{c}}$ Studies included in sensitivity analysis

${ }^{\mathrm{d}}$ Studies included in $65 \pm 5$ analysis

${ }^{\mathrm{e}}$ Studies with $>10$ years follow-up

bowel motion frequency. The weighted mean daytime bowel frequency was 5.88 versus 6.06 in the younger $(n=1649)$ and older groups $(n=299)$. Nocturnal bowel frequency was 1.26 versus 1.96 in younger $(n=2072)$ and older $(n=331)$ groups.

Faecal incontinence Incontinence episodes were considered by all included studies. However, again, heterogeneity in reporting methods meant it was impossible to combine data fully across all studies. Therefore, we have considered incontinence as follows: 1 . Perfect/near perfect continence rates; 2. Daytime and night-time incontinence rates; 3 . Type of incontinence.

Four studies [1, 16-18] gave indication of perfect or nearperfect continence rates. Overall, $74.75 \%$ of the younger patients ( $n=1353)$ versus $55.09 \%$ of older patients $(n=285)$ experienced perfect or near-perfect continence $\left(\chi^{2}=51.1081 \mathrm{df} ; p<0.0001\right)$.

Four studies considered daytime and night-time incontinence rates $[1,13,19,20]$.

Dayton et al. [19] discusses frequencies as never/occasional/often/daily. Therefore, often/daily were combined to give a comparative daytime and night-time incontinence rate. Daytime incontinence rates were significantly higher in the older group (13.95 versus $5.56 \%, \chi^{2}=18.352, p<0.0001$ ), as were night-time incontinence rates (29.65 versus $12.53 \%$, $\left.\chi^{2}=38.624, p<0.0001\right)$.

Delaney et al. [16] discuss nocturnal seepage. At 1 year following surgery, $34 \%$ of younger versus $49 \%$ of older patients experienced nocturnal seepage $\left(\chi^{2}=13.583, \mathrm{p}=0.0002\right)$.

The type of soiling encountered was discussed in four studies $[10,17,18,20]$. Overall, $7.37 \%$ of younger versus $11.04 \%$ of older patients reported incontinence to mucus or flatus only $\left(\chi^{2} 1.9277, p=0.165\right)$, whereas $4.19 \%$ younger versus $5.06 \%$ of older patients reported incontinence to faeces $\left(\chi^{2} 0.2283, p=0.633\right)$.

Incontinence scoring system The usage of incontinence scoring systems in reporting results was scarce, with only Takao et

Table 5 Postoperative complications with age cut-off $50 \pm 5$ years

\begin{tabular}{|c|c|c|c|c|c|c|}
\hline & No. of younger $N(\%)$ & No. of older $N(\%)$ & Total young & Total old & Chi-squared value & $p$ value \\
\hline Leak & $65(6.94)$ & $7(5.56)$ & 937 & 126 & 0.336 & 0.562 \\
\hline Stenosis & $72(8.59)$ & $20(12.27)$ & 838 & 163 & 2.212 & 0.137 \\
\hline Ischaemic bowel & $3(1.60)$ & $1(3.57)$ & 188 & 28 & 0.523 & 0.469 \\
\hline Ischaemic pouch & $2(1.06)$ & $1(3.57)$ & 188 & 28 & 1.119 & 0.290 \\
\hline Abscess formation & $39(9.40)$ & $9(6.87)$ & 415 & 131 & 0.793 & 0.373 \\
\hline Cutaneous fistula & $26(6.27)$ & $4(3.05)$ & 415 & 131 & 1.978 & 0.160 \\
\hline Vaginal fistula & $11(2.65)$ & $3(2.29)$ & 415 & 131 & 0.052 & 0.820 \\
\hline Other fistula & $4(0.96)$ & $0(0)$ & 415 & 131 & 1.272 & 0.259 \\
\hline Small bowel obstruction & $143(17.06)$ & $17(10.43)$ & 838 & 163 & 4.473 & 0.034 \\
\hline Pouch excision/failure & $210(5.47)$ & $22(4.80)$ & 3839 & 458 & 0.238 & 0.626 \\
\hline Pouchitis & $172(20.53)$ & $23(14.11)$ & 838 & 163 & 3.580 & 0.058 \\
\hline Mortality & $2(0.17)$ & $2(0.87)$ & 1164 & 229 & 3.289 & 0.070 \\
\hline
\end{tabular}

Numbers in italics are statistically significant at $P<0.05$ 
Table 6 Postoperative complications with age cut-off of $65 \pm 5$ years

\begin{tabular}{|c|c|c|c|c|c|c|}
\hline & $\begin{array}{l}\text { No. of younger } \\
N(\%)\end{array}$ & $\begin{array}{l}\text { No. of older } \\
N(\%)\end{array}$ & Total young & Total old & $\begin{array}{l}\text { Chi-squared } \\
\text { value }\end{array}$ & $p$ value \\
\hline Leak & $5(4.39)$ & $1(1.67)$ & 114 & 60 & 0.247 & 0.619 \\
\hline Stenosis & $22(5.15)$ & $5(1.17)$ & 427 & 77 & 0.043 & 0.8366 \\
\hline Vaginal fistula & $10(2.54)$ & $0(0)$ & 394 & 44 & 0.288 & 0.5913 \\
\hline Small bowel obstruction & $46(10.77)$ & $6(7.79)$ & 427 & 77 & 0.346 & 0.5566 \\
\hline Pouch excision/failure & $133(6.36)$ & $4(4.49)$ & 2092 & 89 & 0.237 & 0.6266 \\
\hline Pouchitis & $50(11.71)$ & $9(11.69)$ & 427 & 77 & 0.000 & 0.9957 \\
\hline Mortality & $1(0.23)$ & $0(0)$ & 427 & 77 & 0.181 & 0.6708 \\
\hline \multicolumn{7}{|l|}{ Medical complications } \\
\hline Dehydration & $27(23.68)$ & $36(60)$ & 114 & 60 & 20.901 & 0.0001 \\
\hline UTI & $4(3.51)$ & $3(5)$ & 114 & 60 & 0.005 & 0.9442 \\
\hline MI & $1(0.877)$ & $1(1.67)$ & 114 & 60 & 0.216 & 0.6424 \\
\hline LRTI & $6(5.26)$ & $5(8.33)$ & 114 & 60 & 0.215 & 0.6431 \\
\hline PE & $3(2.63)$ & $1(1.67)$ & 114 & 60 & 0.163 & 0.6864 \\
\hline
\end{tabular}

UTI urinary tract infection, $M I$ myocardial infarction, $L R T I$ lower respiratory tract infection, $P E$ pulmonary embolus

Numbers in italics are statistically significant at $P<0.05$

al. [9] employing the Cleveland Clinic Incontinence Scoring System and Tan et al. [20] using a different 12-point scoring system to report functional results. Neither author identified a significant difference in scores between the younger and older age groups.

Pad and medication usage The usage of pads and medications was not frequently reported, and heterogeneity of reported data meant no combination of data was possible.

Dayton et al. [19] reported no significant difference in medication usage between older and younger patients.

Tan et al. report a daytime pad usage of 2.75 versus $16.7 \%$ in younger and older groups $\left(\chi^{2}=5.10, p=0.024\right)$, and a night-time pad usage of 8.25 versus $16.7 \%(p=0.389)$ in older and younger groups. Medication usage was 33 versus $41.7 \%(p=0.323)$ in younger and older groups.

Other markers of function Two papers $[18,20]$ discussed the ability to discriminate between flatus and faeces. Overall, $15.75 \%$ younger versus $23.81 \%$ older patients were unable to discriminate, but this did not reach statistical significance ( $p=0.3409$ ). Lewis et al. [18] found that $14 / 18$ older vs 17/ 18 younger patients were ability to defer defecation for $>15$ min.

Patient satisfaction and quality of life data Three papers considered patient satisfaction and/or quality of life data [9, $13,16]$.

Patient satisfaction with surgery Takao discusses patient satisfaction, describing patients as either 'worse', 'no change' or 'improved'. In those $>60,12$ patients $(71 \%)$ reported an improvement in satisfaction postoperatively, and 5 (29\%) reported no change. In the younger age group, $<40,44$ patients $(76 \%)$ reported improvement, 12 patients $(21 \%)$ reported no change and 2 patients ( $3 \%$ ) reported worsening.

Delaney et al. [16] reported patient satisfaction with outcome of surgery as a mean score out of 10 ; at 1 year, this was 9.1 in the younger $(<45)$ age group and 8.32 in the older $(>55)$ age group.

Quality of life Delaney et al. use the Cleveland global quality of life score (CGQL) in order to discuss differences in QoL between age groups. Patients under than 45 years of age tended to have a better overall score compared with older patients at 1,3 and 5 years post surgery.

Chapman et al. [13] examined differences in restrictions between age groups. There were no significant differences detected in sexual, work, social or family activities noted between those $<45$ and those $>45$ at follow-up, with the exception of sexual function beyond 5 years which was significantly worsened in the $>55$ age category.

Seventy percent of patients $>55$ reported improved or not affected social activities following surgery; 84 and $82 \%$ reported that undergoing IPAA had improved or not affected work and family life.

Anorectal physiology Anorectal physiology was compared in three studies $[9,18,19]$. Differences in reporting data made overall statistical analysis difficult. Dayton et al. found that preoperative resting and squeeze pressures were significantly lower in patients $>55$ years; however, there were no significant differences postoperatively in these values between age groups. Similarly, Takao et al. and Lewis et al. found no significant differences in resting and squeeze pressures pre- and postoperatively between different age groups. 


\section{Sensitivity analysis}

Sensitivity analysis was performed on comparable functional outcome data with a strict age cut-off of 50 years, further excluding two papers $[17,19]$. The total numbers included in sensitivity analysis were 3781 versus 448 patients in the older versus younger groups. Mean bowel actions per $24 \mathrm{~h}$ were $5.36 \pm 2.48$ versus $6.83 \pm 3.90$ motions in younger $(n=571)$ and older $(n=187)$ groups (unpaired $t$ test $p<0.0001)$.

The difference in rates of near/perfect incontinence between older and younger groups remained highly significant (75.58 versus $55.16 \%, \chi^{2}=47.658, p<0.0001$ ), as did the daytime $(p<0.0001)$ and night-time $(p<0.0001)$ incontinence rates. No differences were detected in the type of soilage experienced.

\section{Age $65 \pm 5$ years}

Two additional papers $[2,21]$ considered a more elderly population, with Pellino et al. using age 70 as a cut-off and Pinto et al. using age 65 . These papers were considered alongside patient subgroups from Delaney et al. $(>65, n=39)$, Sun Ho et al. $(>70, n=17)$ and Tan et al. $(>70, n=5)$ with patients divided into older $(n=104)$ and younger $(n=1981)$ categories.

Complication rates, functional outcomes and quality of life were compared between groups.

\section{Complication rates}

Complication rates were compared across three papers $[2,16$, 21]. Table 6 gives the results. With the exception of dehydration and electrolyte imbalance (23.68 versus $60 \%$, $p<0.0001$ ), there were no significant differences seen in postoperative complication rates or mortality between groups.

\section{Functional outcomes}

The mean number of bowel motions per $24 \mathrm{~h}$ was 6.23 versus 6.50 in the younger and older groups $[2,10,21] .77 .99 \%$ of younger compared with $66.30 \%$ of older patients had perfect continence $\left(\chi^{2}=6.265, p=0.0123\right)[10,16,21]$. Pellino et al. [2] did not find a significant difference in either daytime or night-time incontinence rates between older and younger patients; however, they did report a statistically significant increase in the use of anti-diarrhoeal agents in older patients $(p=0.03)$.

\section{Quality of life}

Two papers $[2,16]$ considered quality of life following surgery. Unfortunately, both papers used different scoring systems therefore results could not be amalgamated. Pellino et al. found no significant difference in Inflammatory Bowel Disease Questionnaire (IBDQ) results between the older and younger patients. The quality of life data from Delaney and colleagues has been discussed previously.

\section{Long-term outcomes}

Long-term outcomes ( $>10$ years) were compared in three studies $[13,15,16]$. The data from Kiran et al. was used preferentially over that given by Delaney et al. due to the longer follow-up and completeness of long-term follow-up.

Unfortunately, due to the heterogeneity in methods of reporting functional outcomes in these papers, it was not possible to perform statistical analysis.

Kiran et al. [15] followed up 189 patients $<35$ years, 184 patients aged $35-55$ years and 23 patients $>55$ years. Overall, there was an increase in the incidence of incontinence and urgency across all age groups during the 15 years of followup, with increased pad usage. However, patient satisfaction and quality of life data overall was stable over the 15-year time-frame, with no significant differences between the age groups. Mean stool frequency declined in the younger patients, but remained stable in the older patients, whereas nocturnal stool frequency increased significantly in younger patients. Daytime seepage increased significantly in older patients, and for those aged 35-55 years nocturnally.

Chapman et al. had 10-year follow-up data available for 892 patients $<45$ years, 118 patients $45-55$ years and 25 patients $>55$ years of age. They reported that whilst patients $>55$ suffered significantly more daytime and night-time incontinence at 1 and 3 years compared to those $<45$, this was no longer apparent at 5 and 10 years follow-up, with no significant difference in incontinence rates between younger and older groups. Patients $>55$ years had a daytime incontinence rate of $15.2 \%$ at 1 year, and $12 \%$ at 10 years, and those $<45$ years had a daytime incontinence rate of $4.1 \%$ at 1 year and $4.8 \%$ at 10 years. Night-time incontinence rates in those $>55$ years were $26.1 \%$ at 1 year and $24 \%$ at 10 years and $9.4 \%$ at 1 year and $12.2 \%$ at 10 years in those $<45$ years.

With the exception of sexual restrictions, which was significantly more common in those older than 55 years at 5 and 10 years ( 3.1 versus $21.7 \%$ at 10 years follow-up, $p<0.01$ ), there was no significant difference in other life areas such as work, travel, social, family relations and sport.

\section{Discussion}

The incidence of inflammatory bowel disease in the elderly (>60 years) is currently $10-15 \%$ [22], with the majority presenting in their 60 s; however, $25 \%$ present in their seventies and a further $10 \%$ in their eighties [23]. With improving 
healthcare delivery meaning people live for longer, these figures are set to increase.

Medical treatment in ulcerative colitis is similar across all age groups, with similar response rates to treatment [24]. Failure of medical treatment remains the most common reason for proceeding to surgical intervention; however, the presence of dysplasia is another common indication amongst this patient population [25], with Bauer et al. demonstrating a significantly higher rate of dysplasia and malignancy in older patients [1]. A recent meta-analysis found that older patients with ulcerative colitis were no more likely to undergo surgery when compared to younger patients [26], which is in the region of a third of all cases [4]. This is in spite of the fact that disease severity tends to be less in the older population [23].

The undertaking of major reconstructive surgery in the form of ileoanal pouch creation following proctocolectomy in older patients has been a fairly contentious issue. Initially, it was believed that due to the high incidence of complications, with around a $20 \%$ morbidity [27], that restorative proctocolectomy should not be performed in patients older than 50. Instead patients were left with an end ileostomy, which is in itself associated with a relatively high morbidity, although several studies have demonstrated a similar quality of life when compared to the general population [28, 29]. More recent studies, including those in this review have advised that IPAA can be safely performed in older patients, even those in their 70 s or 80 s $[30,31]$. Guidance published by the American Society of Colon and Rectal Surgeons recommend that chronological age should not be a reason in itself to deny IPAA in older patients [32].

This analysis supports the view that in terms of safety, IPAA in patients over 50 is feasible with comparable complication rates to those seen in younger patients. A recent multicentre registry analysis undertaken by Cohan and colleagues [4] which included 2493 patients undergoing IPAA, with 254 above the age of 60 , found that in terms of postoperative complications rates, there was no significant increase in older patients; however, there was an increased length of stay in the older group.

Small-bowel obstruction was found to be significantly more common in younger patients in this review. The reasons as to why this is remain unclear; however, this difference was not replicated in the separate analysis of patients over 65 . Otherwise, the only other difference worthy of note was the significantly increased risk of dehydration and electrolyte imbalance (23.68 versus $60 \%$ in those over 65 ). This was in the context of loop ileostomy formation in the early postoperative phase. Several studies have shown dehydration to be the most common cause of patient readmission following ileostomy creation [33, 34]. Paquette et al. [35] found age $>50$ to be an independent factor for a readmission with renal failure following ileostomy creation, with IPAA associated with readmission for dehydration in their series of 201 patients. Overall, they found that 30-day readmission rates with dehydration following loop ileostomy creation were in the region of $25 \%$. Sixteen percent of those $>50$ versus $5 \%$ of those $<50$ were admitted within 30-days with renal failure secondary to ileostomy. The rate of renal failure with IPAA was $8 \%$ in $>50$ versus $7 \%$ in $<50$. The reasons as to why the rates of dehydration and electrolyte imbalance in the papers included in the review are much higher are unclear; this may be secondary to these patients being at the extremes of age i.e. $>65$ years old, where there is more likely to be a degree of pre-existing renal impairment or the concomitant use of diuretic agents.

With regards to functional outcomes, there was a significant difference noted in terms of incontinence rates, with older patients significantly more likely to suffer incontinence, both during the day and nocturnally. The number of bowel motions per $24 \mathrm{~h}$ was statistically higher in those over 50 years of age; however, the likely impact of this on overall daily living is likely to be minimal, with an average of only one extra visit to the toilet in $24 \mathrm{~h}$. Functional results were seen to decline across all age groups over time. In both of the papers where long-term functional data was analysed, the significantly different incontinence rates between older and younger groups seen at 1 year were diminished in the longer term.

The authors Pellino et al. have published a further paper discussing outcomes with patients over the age of 80 years [31]. Although at 6 months older patients had more nocturnal seepage, anti-diarrhoeal usage and a trend towards higher daytime incontinence rates, these issues were largely resolved by 12 months, with only nocturnal seepage more common in the elderly patient group. Most importantly, all older patients were satisfied with their outcomes and would undergo surgery again. Patient satisfaction and perceived quality of life following surgery are arguably the most important aspect of this review, as beyond ensuring comparable outcomes in terms of safety, the acceptability of results to patients is of utmost importance. Unfortunately, only three papers considered this outcome; however, these showed that overall patient satisfaction and quality of life were maintained following surgery in older patients, with the exception of Delaney et al. [16], who did report a significant difference in CGQL scores in older patients at 1,3 and 5 years following surgery. Happiness levels were comparable across all ages. These positive outcomes with respect to satisfaction with surgery and QoL are in spite of the statistically significant increase in day and night incontinence rates.

Overall, the outcomes shown demonstrate that the consideration of RPC in older patients is warranted, with acceptable complication rates not dissimilar to those seen in younger patients. Careful fluid balance must however be achieved to avoid dehydration, in particular when older patients have a temporary loop ileostomy formed as this predisposes them to a significantly higher risk of electrolyte imbalance and dehydration. Additionally, the operating surgeon should ensure 
that there is at least $200 \mathrm{~cm}$ of small bowel proximal to the site of stoma creation in order to reduce this risk further. A shorter segment of proximal small bowel will also predispose the patient to a greater risk of incontinence, faecal urgency, seepage and looser stool once the stoma is reversed. Older patients should also be counselled as to the higher likelihood of faecal incontinence and nocturnal seepage following stoma reversal.

Further studies should include age-related analysis regarding postoperative quality of life and satisfaction with surgery, as these aspects are fundamental in the decision to recommend this major surgery to older patients.

As with all surgery, thorough patient optimisation and careful case selection are vital, with consideration given to the suitability of each case on its own merit; age as a number alone is insufficient as a basis for decision regarding the type of surgery performed. Patients should receive adequate support with regards to management of any functional deterioration in order to maintain high levels of patient satisfaction and acceptable postoperative quality of life.

\section{Limitations}

The main limitations of this review are related to the heterogeneity of presented data which at times made statistical comparison impossible. Furthermore, the majority of the papers grouped patients according to age alone, with differing disease pathology and operative techniques. Unfortunately, data was not presented in such a way to allow comparison between age groups for separate disease states. Included papers were also in the most part either retrospective or involved retrospective analysis of a prospectively maintained database. In addition, different age cut-offs were employed to define older and younger groups between papers, although sensitivity analysis demonstrated extremely similar outcomes to analysis across all studies.

Open Access This article is distributed under the terms of the Creative Commons Attribution 4.0 International License (http:// creativecommons.org/licenses/by/4.0/), which permits unrestricted use, distribution, and reproduction in any medium, provided you give appropriate credit to the original author(s) and the source, provide a link to the Creative Commons license, and indicate if changes were made.

\section{References}

1. Bauer JJ, Gorfine SR, Gelernt IM, Harris MT, Kreel I (1997) Restorative proctocolectomy in patients older than fifty years. Dis Colon Rectum 40:562-5

2. Pellino G, Sciaudone G, Candilio G, Camerlingo A, Marcellinaro $\mathrm{R}$, Rocco F et al (2013) Complications and functional outcomes of restorative proctocolectomy for ulcerative colitis in the elderly. BMC Surg 13(Suppl 2):S9. doi:10.1186/1471-2482-13-s2-s9
3. Pellino G (2015) Effects of age at disease onset and at treatment on serology in inflammatory bowel diseases. Dig Dis Sci 60:278-9. doi:10.1007/s10620-014-3420-z

4. Cohan JN, Bacchetti P, Varma MG, Finlayson E (2015) Outcomes after ileoanal pouch surgery in frail and older adults. J Surg Res. doi:10.1016/j.jss.2015.04.014

5. Hozo SP, Djulbegovic B, Hozo I (2005) Estimating the mean and variance from the median, range, and the size of a sample. BMC Med Res Methodol 5:13. doi:10.1186/1471-2288-5-13

6. Pemberton JH, Kelly KA, Beart RW Jr, Dozois RR, Wolff BG, Ilstrup DM (1987) Ileal pouch-anal anastomosis for chronic ulcerative colitis. Long-term results. Ann Surg 206:504-13

7. Jorge JM, Wexner SD, James K, Nogueras JJ, Jagelman DG (1994) Recovery of anal sphincter function after the ileoanal reservoir procedure in patients over the age of fifty. Dis Colon Rectum 37:10025

8. Reissman P, Teoh TA, Weiss EG, Nogueras JJ, Wexner SD (1996) Functional outcome of the double stapled ileoanal reservoir in patients more than 60 years of age. Am Surg 62:178-83

9. Takao Y, Gilliland R, Nogueras JJ, Weiss EG, Wexner SD (1998) Is age relevant to functional outcome after restorative proctocolectomy for ulcerative colitis?: prospective assessment of 122 cases. Ann Surg 227:187-94

10. Ho KS, Chang CC, Baig MK, Borjesson L, Nogueras JJ, Efron J et al (2006) Ileal pouch anal anastomosis for ulcerative colitis is feasible for septuagenarians. Colorectal Dis 8:235-8. doi:10.1111/j. 1463-1318.2005.00885.x

11. Metcalf AM, Dozois RR, Kelly KA, Beart RW Jr, Wolff BG (1985) Ileal "J" pouch-anal anastomosis. Clinical outcome. Ann Surg 202: $735-9$

12. Farouk R, Pemberton JH, Wolff BG, Dozois RR, Browning S, Larson D (2000) Functional outcomes after ileal pouch-anal anastomosis for chronic ulcerative colitis. Ann Surg 231:919-26

13. Chapman JR, Larson DW, Wolff BG, Dozois EJ, Cima RR, Pemberton JH et al (2005) Ileal pouch-anal anastomosis: does age at the time of surgery affect outcome? Arch Surg 140:534-9. doi: 10.1001/archsurg.140.6.534, discussion 9-40

14. Erkek AB, Church JM, Remzi FH (2007) Age-related analysis of functional outcome and quality of life after restorative proctocolectomy and ileal pouch-anal anastomosis for familial adenomatous polyposis. J Gastroenterol Hepatol 22:710-4. doi:10. 1111/j.1440-1746.2007.04870.x

15. Kiran RP, El-Gazzaz G, Remzi FH, Church JM, Lavery IC, Hammel J et al (2011) Influence of age at ileoanal pouch creation on long-term changes in functional outcomes. Colorectal Dis 13: 184-90. doi:10.1111/j.1463-1318.2009.02127.x

16. Delaney CP, Fazio VW, Remzi FH, Hammel J, Church JM, Hull TL et al (2003) Prospective, age-related analysis of surgical results, functional outcome, and quality of life after ileal pouch-anal anastomosis. Ann Surg 238:221-8. doi:10.1097/01.sla.0000080825. 95166.26

17. Pescatori M, Mattana C (1990) Factors affecting anal continence after restorative proctocolectomy. Int J Color Dis 5:213-8

18. Lewis WG, Sagar PM, Holdsworth PJ, Axon AT, Johnston D (1993) Restorative proctocolectomy with end to end pouch-anal anastomosis in patients over the age of fifty. Gut 34:948-52

19. Dayton MT, Larsen KR (1996) Should older patients undergo ileal pouch-anal anastomosis? Am J Surg 172:444-7. doi:10.1016/ S0002-9610(96)00253-X, discussion 447-8

20. Tan HT, Connolly AB, Morton D, Keighley MR (1997) Results of restorative proctocolectomy in the elderly. Int J Color Dis 12:319 22

21. Pinto RA, Canedo J, Murad-Regadas S, Regadas SF, Weiss EG, Wexner SD (2011) Ileal pouch-anal anastomosis in elderly patients: is there a difference in morbidity compared with younger patients? Colorectal Dis 13:177-83. doi:10.1111/j.1463-1318.2009.02097.x 
22. Hussain SW, Pardi DS (2010) Inflammatory bowel disease in the elderly. Drugs Aging 27:617-24. doi:10.2165/11537340000000000-00000

23. Gisbert JP, Chaparro M (2014) Systematic review with meta-analysis: inflammatory bowel disease in the elderly. Aliment Pharmacol Ther 39:459-77. doi:10.1111/apt.12616

24. del Val JH (2011) Old-age inflammatory bowel disease onset: a different problem? World J Gastroenterol 17:2734-9. doi:10. 3748/wjg.v17.i22.2734

25. Ross H, Steele SR, Varma M, Dykes S, Cima R, Buie WD et al (2014) Practice parameters for the surgical treatment of ulcerative colitis. Dis Colon Rectum 57:5-22. doi:10.1097/DCR. 0000000000000030

26. Shung DL, Abraham B, Sellin J, Hou JK (2015) Medical and surgical complications of inflammatory bowel disease in the elderly: a systematic review. Dig Dis Sci 60:1132-40. doi:10.1007/s10620014-3462-2

27. Parray FQ, Wani ML, Malik AA, Wani SN, Bijli AH, Irshad I et al (2012) Ulcerative colitis: a challenge to surgeons. Int J Prev Med 3: $749-63$

28. Umanskiy K, Fichera A (2010) Health related quality of life in inflammatory bowel disease: the impact of surgical therapy. World J Gastroenterol 16:5024-34

29. Camilleri-Brennan J, Steele RJ (2001) Objective assessment of quality of life following panproctocolectomy and ileostomy for ulcerative colitis. Ann R Coll Surg Engl 83:321-4
30. Delaney CP, Dadvand B, Remzi FH, Church JM, Fazio VW (2002) Functional outcome, quality of life, and complications after ileal pouch-anal anastomosis in selected septuagenarians. Dis Colon Rectum 45:890-4, discussion 4

31. Pellino G, Sciaudone G, Candilio G, De Fatico GS, Landino I, Canonico S et al (2014) Restorative proctocolectomy with ileal pouch-anal anastomosis is safe and effective in selected very elderly patients suffering from ulcerative colitis. Int J Surg 12(Suppl 2): S56-9. doi:10.1016/j.ijsu.2014.08.380

32. Cohen JL, Strong SA, Hyman NH, Buie WD, Dunn GD, Ko CY et al (2005) Practice parameters for the surgical treatment of ulcerative colitis. Dis Colon Rectum 48:1997-2009. doi:10.1007/s10350005-0180-Z

33. Tyler JA, Fox JP, Dharmarajan S, Silviera ML, Hunt SR, Wise PE et al (2014) Acute health care resource utilization for ileostomy patients is higher than expected. Dis Colon Rectum 57:1412-20. doi: $10.1097 /$ dcr.0000000000000246

34. Messaris E, Sehgal R, Deiling S, Koltun WA, Stewart D, McKenna $\mathrm{K}$ et al (2012) Dehydration is the most common indication for readmission after diverting ileostomy creation. Dis Colon Rectum 55:175-80. doi:10.1097/DCR.0b013e31823d0ec5

35. Paquette IM, Solan P, Rafferty JF, Ferguson MA, Davis BR (2013) Readmission for dehydration or renal failure after ileostomy creation. Dis Colon Rectum 56:974-9. doi:10.1097/DCR. 0b013e31828d02ba 